\title{
Successful Treatment of Pituitary Germinoma with Etoposide, Cisplatin, Vincristine, Methotrexate and Bleomycin Chemotherapy Without Radiotherapy
}

\author{
AMINA SCHERZ ${ }^{*}$, KATRIN FELLER ${ }^{2 *}$, SABINA BEREZOWSKA $^{3}$, VERA GENITSCH $^{3}$ and MARTIN ZWEIFEL ${ }^{1}$ \\ Departments of ${ }^{1}$ Medical Oncology, and ${ }^{2}$ Diabetology, Endocrinology, \\ Clinical Nutrition and Metabolism, University Hospital Bern, Bern, Switzerland; \\ ${ }^{3}$ Institute of Pathology, University of Bern, Bern, Switzerland
}

\begin{abstract}
We report on the case of a 25-year-old man with pituitary germinoma. The patient had noticed polydipsia, reduced sexual function, and loss of body hair. Laboratory investigations confirmed panhypopituitarism including diabetes insipidus. Magnetic resonance imaging of the brain showed a $14 \times 8.4 \mathrm{~mm}$ enhancing lesion of the pituitary stalk and histopathology of the neurosurgical biopsy confirmed pituitary germinoma. The patient was treated with 3 cycles of chemotherapy, consisting of $150 \mathrm{mg} / \mathrm{m}^{2}$ etoposide and $75 \mathrm{mg} / \mathrm{m}^{2}$ cisplatin, with the administration of intrathecal $12.5 \mathrm{mg}$ methotrexate, on day one, alternating every 10 to 11 days with $1 \mathrm{mg} / \mathrm{m}^{2}$ vincristine, $1,000 \mathrm{mg} / \mathrm{m}^{2}$ methotrexate on day 1 and $30 \mathrm{mg} / \mathrm{m}^{2}$ bleomycin on day 2 . MRI scans showed lasting complete remission more than a year after completion of chemotherapy. Intracranial germinomas are exquisitely sensitive to radiation. However, due to concerns of side-effects (radiation-associated tumour, relapse outside the radiation field, mental and pituitary hormonal dysfunction), and after discussing both approaches carefully with the patient, the decision was made to treat his pituitary germinoma with chemotherapy alone. Further studies should address the question as to whether a modulated approach, using radiotherapy only as a salvage in patients with relapse, might result in a better overall outcome, given the potentially harmful long-term side-effects of radiotherapy to the brain.
\end{abstract}

*These Authors contributed equally to this study.

Correspondence to: Martin Zweifel, MD, Ph.D., Department of Medical Oncology, University Hospital Bern, 3010 Bern, Switzerland, Fax: +41 316324116, Tel: +41 316324114, e mail: martin.zweifel@insel.ch

Key Words: Pituitary germinoma, germ cell tumour, panhypopituitarism, diabetes insipidus, chemotherapy, radiotherapy.
Intracranial germ cell tumours (GCTs) are a rare entity with excellent prognosis if treated with combined chemoradiation. However, long-term toxicity of radiotherapy is of concern and it is still debated whether a chemotherapy-only approach with salvage radiotherapy, if needed, is feasible.

We report on the case of a 25 -year-old man with pituitary germinoma.

\section{Case Report}

The patient was referred to the endocrinology unit for hypogonadotropic hypogonadism. For over a year, the patient had noticed polydipsia (daily fluid intake of 5 to 61 ), reduced sexual function (reduced libido, lack of spontaneous erections in the morning) and loss of body hair. There were no signs of galactorrhoea or mastodynia. Because of a slightly elevated serum prolactin level and a possible lesion measuring $4 \mathrm{~mm}$ in the anterior pituitary region, microprolactinoma was suggested and treatment with cabergolin was started. As there was no improvement in hypogonadotropic hypogonadism despite dopaminergic therapy, the patient was referred to our Department of Diabetology, Endocrinology, Clinical Nutrition and Metabolism for a second opinion. The patient reported increasing fatigue and loss of energy as well as complete loss of sexual function. Family history was unremarkable except for hypothyroidism in the patient's mother. Physical examination showed hypotension $(90 / 55 \mathrm{mmHg})$, a lean patient (body mass index $22.9 \mathrm{~kg} / \mathrm{m}^{2}$ ) with loss of muscle mass and body hair, and a slightly reduced testicular volume of $12 \mathrm{ml}$ bilaterally. Laboratory investigations confirmed hypogonadotropic hypogonadism, a decrease in prolactin level under cabergolin treatment, and, compared to the blood values of 2 months earlier, newly-developed corticotropic, thyrotropic and somatotropic pituitary insufficiency, as well as diabetes insipidus (confirmed by a modified thirst test), confirming panhypopituitarism. Serum levels of human chorionic gonadotropin beta ( $\beta \mathrm{HCG}$ ) and $\alpha$-fetoprotein (AFP) 
were normal. Magnetic resonance imaging (MRI) of the pituitary region revealed an inhomogeneous $14 \times 8.4 \mathrm{~mm}$ enhancement of the pituitary stalk. Neurosurgical biopsy was performed and histopathology revealed a pituitary germinoma (Figure 1). Computed tomography (CT) of the thorax and abdomen, as well as urological ultrasound, did not show a testicular mass or any other extra-testicular lesion.

The patient was treated with three cycles of chemotherapy, including the application of intrathecal methotrexate, consisting of $150 \mathrm{mg} / \mathrm{m}^{2}$ etoposide and $75 \mathrm{mg} / \mathrm{m}^{2}$ cisplatin (EP), including intrathecal $12.5 \mathrm{mg}$ methotrexate followed by $7.5 \mathrm{mg}$ folinic acid at 24 hours and 48 hours on day one, alternating every 10 to 11 days with $1 \mathrm{mg} / \mathrm{m}^{2}$ vincristine, $1,000 \mathrm{mg} / \mathrm{m}^{2}$ methotrexate on day 1 and bleomycin $30 \mathrm{mg} / \mathrm{m}^{2}$ on day $2(\mathrm{OMB})$, starting $15 \mathrm{mg}$ folinic acid every 6 hours for 10 doses 32 hours after the start of methotrexate $(1,2)$.

Treatment was well tolerated, with fatigue being virtually the only major side-effect. An MRI scan of the sella was performed 3 weeks after the last cycle of chemotherapy, which showed complete remission of the pituitary germinoma. At more than a year after completion of treatment the patient remains in complete remission (Figure 2).

While the patient has an excellent chance of being cured of his tumour, panhypopituitarism persists, requiring hormonal substitution with desmopressin nasal spray once daily, $10 \mathrm{mg}$ hydrocortisone p.o. twice daily, $100 \mu \mathrm{g}$ levothyroxin p.o. once daily, and intramuscular injection of $1,000 \mathrm{mg}$ testosterone undecanoate every 3 months. A change to gonadotropin substitution is planned as soon as the patient has the desire to achieve fertility.

\section{Discussion}

Intracranial germ cell tumours (GCTs) are a rare entity, accounting for $3-5 \%$ of paediatric intracranial tumours, but only $0.4-1 \%$ of intracranial tumours in adults. Pineal germinomas occur more often in male patients, while suprasellar germinomas are more frequent in females (3). According to the World Health Organization (WHO) classification system, intracranial GCTs are divided into germinomas and non-germinomatous GCTs (4). Intracranial GCTs can also be subdivided into secreting and nonsecreting tumours. Classically, secreting GCTs are defined as GCTs with cerebrospinal fluid (CSF) AFP $>10 \mu \mathrm{g} / 1$ (or above the institutional normal range) and/or a CSF $\beta \mathrm{HCG}$ level $>50 \mathrm{IU} / 1$. Secreting GCTs are considered to be more aggressive and carry a poorer prognosis than non-secreting GCTs $(5,6)$. A total of $73-86 \%$ of intracranial GCTs are pure germinomas. They are generally non-secreting, although a small proportion may correlate with elevated $\beta \mathrm{HCG}$ level in the CSF or serum. An elevated $\beta \mathrm{HCG}$ level is ascribed to syncytiotrophoblasts that may be scattered within germinomas $(5,6)$.
Intracranial germinomas are exquisitely sensitive to radiation. Most contemporary series reported long-term progression-free survival (PFS) rates $>90 \%$ especially for patients with localized pure germinomas after radiation therapy alone (7-13).

However, three main concerns persist regarding the use of radiotherapy: firstly, the high rate of radiationassociated tumours; secondly, distant relapse or relapse outside the radiation field; and thirdly, mental and pituitary hormonal dysfunction after radiotherapy. Considering the average age of diagnosis (i.e. 11 years) and that such a patient is likely to live another 69 to 74 years (14), the increased risk of radiation-associated tumours is worrisome. In a recent study over a 10-year period including patients treated for intracranial germinoma, 27 cases of radiation-induced tumour were identified, including meningioma, sarcoma, diffuse astrocytoma, and medulloblastoma (15). A further potential sequela includes radiation-induced cavernoma (16). Another concern is distant relapse or relapse at the margin of radiotherapy, which would not have occurred using systemic chemotherapy (17-19). It is important to consider that the neurotoxic effects of radiotherapy are of relevance. Radiotherapy may cause mental and pituitary hormonal dysfunction. In retrospective series, up to $50 \%$ of patients showed remarkably low mental function after radiotherapy and up to $90 \%$ of patients needed hormone replacement (17, 20-23). Pituitary dysfunction present before treatment persisted or even worsened after tumour remission, except for patients with small and localised neurohypophyseal germinomas. The poor endocrine results were considered to be largely radiation-related (22).

Chemotherapy alone led to quick and early responses, but a high relapse rate in three studies (24-26). In all these studies, either carboplatin or cisplatin and etoposide, combined with either bleomycin with/without cyclophosphamide were used. This choice of chemotherapy drugs is somewhat surprising, since the cytotoxic effects of cisplatin, etoposide, and bleomycin, are notorious for failing in sanctuaries such as the testis (27). Due to the blood-brain barrier, making the brain another sanctuary, CSF concentrations of these drugs remain low after intravenous administration, with maximum levels achieved by cisplatin ( $20 \%$ of total plasma concentration) (2830 ), followed by cyclophosphamide (17\%) (31), and etoposide (7\%). CSF penetration of carboplatin has been shown to be as low as $2.6 \%$ (30). In contrast, using methotrexate, a drug routinely administered for the treatment of various types of GCT, cytotoxic concentrations can be achieved through the infusion of high doses, which later are antagonised with folinic acid (32).

The treatment of primary intracranial GCTs using a combination of EP/OMB without radiotherapy was used as long as 30 years ago with excellent results $(1,2)$. It is likely 

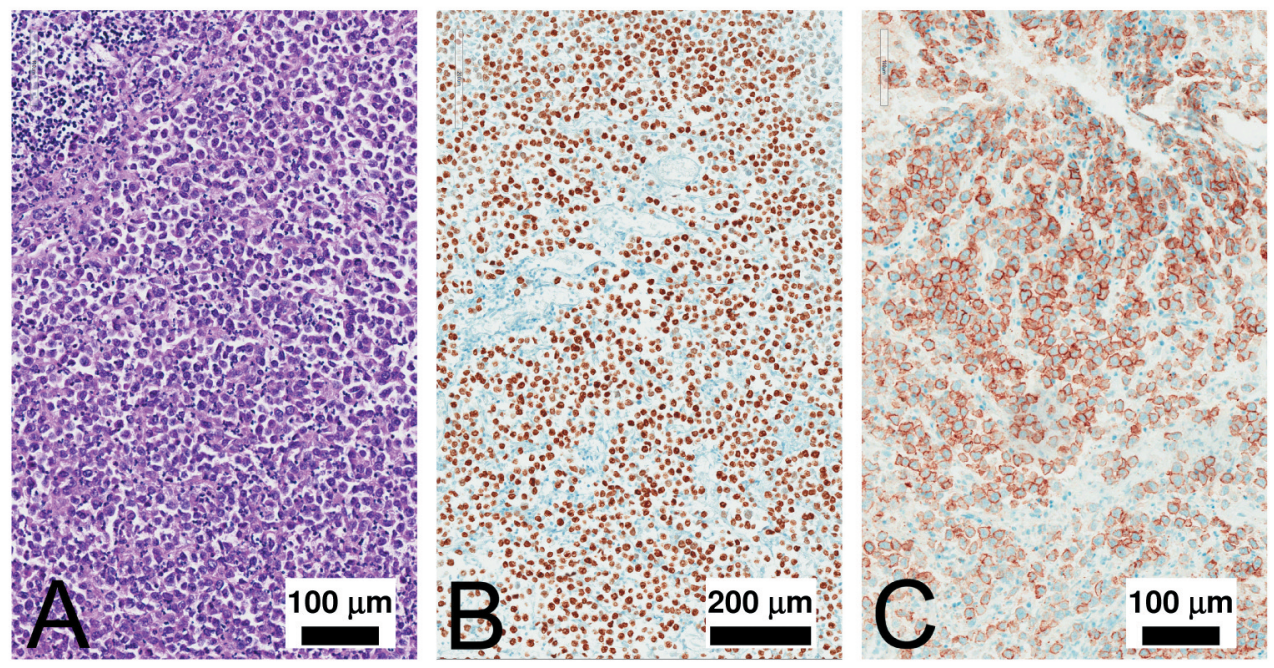

Figure 1. Histology of the pituitary biopsy. Large, discohesive, neoplastic cells in a brisk lymphocytic background are seen upon haematoxylin and eosin staining (A). The tumour cells were found to express SALL4 (B) and CD117/c-KIT (C), which are both characteristic of germinoma.
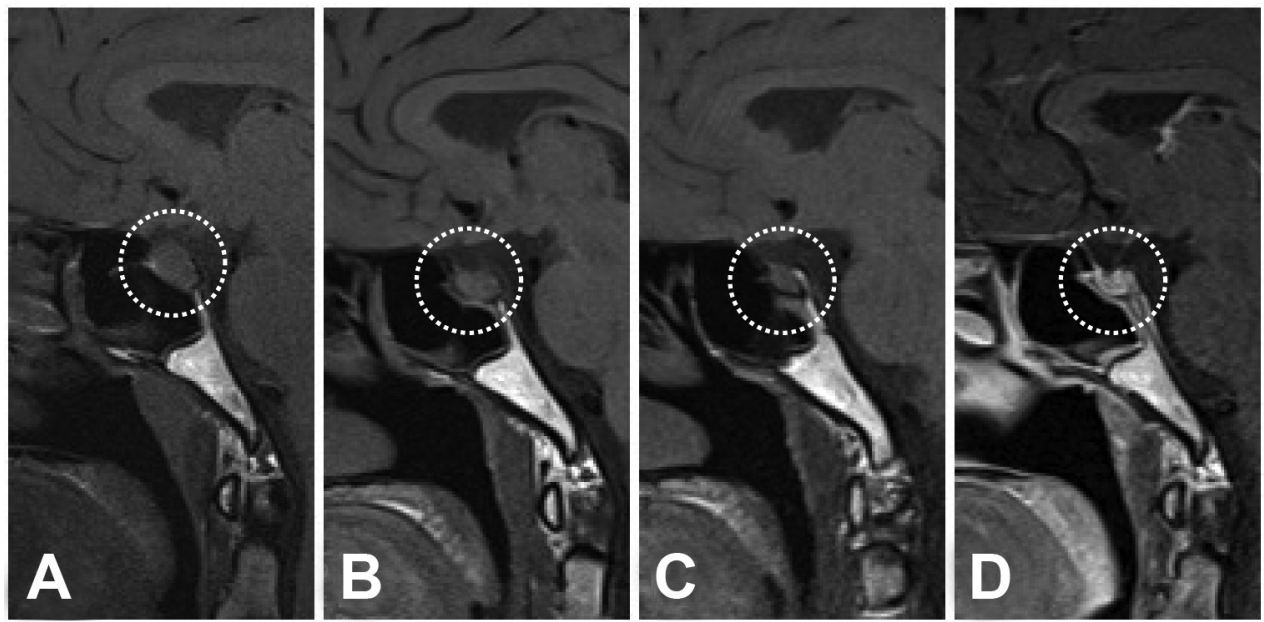

Figure 2. Magnetic resonance imaging of the brain showing the pituitary gland (dotted circle), which initially was enlarged to $14 \times 8.4$ mm (A), and then gradually reduced in size to $8.7 \times 5.5 \mathrm{~mm}$ at 3 weeks $(B), 6.8 \times 4.9 \mathrm{~mm}$ at 5 months $(C)$, and to $5.8 \times 4.5 \mathrm{~mm}$ at lyear after completion of chemotherapy $(D)$.

that this treatment was less used after publication of the convincing results with cisplatin, etoposide, and bleomycin alone in the treatment of metastatic GCTs (33), however, thereby disregarding the difficulties in overcoming the blood-brain barrier in primary intracranial GCT and GCTs metastatic to the brain.

In our case, after discussing both approaches carefully with the patient, the conclusion that chemotherapy alone may be quite effective in oncological as well as endocrinological terms (20) and that radiotherapy might be reserved for relapse $(34,35)$ led us to the decision to treat this patient's pituitary germinoma with chemotherapy alone. Further studies should address the question as to whether a modulated approach using radiotherapy only as salvage therapy in tumours relapsing after chemotherapy might result in a better overall outcome, given the potentially harmful long-term side-effects of radiotherapy to the brain. 


\section{References}

1 Newlands ES: VP-16 in combinations for first-line treatment of malignant germ-cell tumors and gestational choriocarcinoma. Semin Oncol 12: 37-41, 1985.

2 Rustin GJ, Newlands ES, Bagshawe KD, Begent RH and Crawford SM: Successful management of metastatic and primary germ cell tumors in the brain. Cancer 57: 2108-2113, 1986.

3 Villano JL, Propp JM, Porter KR, Stewart AK, Valyi-Nagy T, Li $\mathrm{X}$, Engelhard $\mathrm{HH}$ and McCarthy BJ: Malignant pineal germ-cell tumors: an analysis of cases from three tumor registries. Neuro Oncol 10: 121-130, 2008.

4 Rosenblum MK, Nakazato Y and Matsutani M: CNS germ cell tumors. In: WHO Classification of Tumours of the Central Nervous System. Louis D, Ohgaki H, Wiestler O and Cavenee WK (eds.). Albany, NY: WHO Publication Center, p. 197, 2007.

5 Ho DM and Liu HC: Primary intracranial germ cell tumor. Pathologic study of 51 patients. Cancer 70: 1577-1584, 1992.

6 Washiyama K, Sekiguchi K, Tanaka R, Yamazaki K, Kumanishi $\mathrm{T}$ and Oyake Y: Immunohistochemical study on AFP, HCG and PLAP in primary intracranial germ cell tumors. Prog Exp Tumor Res 30: 296-306, 1987.

7 Bamberg M, Kortmann RD, Calaminus G, Becker G, Meisner C, Harms D and Gobel U: Radiation therapy for intracranial germinoma: results of the German cooperative prospective trials MAKEI 83/86/89. J Clin Oncol 17: 2585-2592, 1999.

8 Borg M: Germ cell tumours of the central nervous system in children-controversies in radiotherapy. Med Pediatr Oncol 40: 367-374, 2003.

9 Haddock MG, Schild SE, Scheithauer BW and Schomberg PJ: Radiation therapy for histologically confirmed primary central nervous system germinoma. Int J Radiat Oncol Biol Phys 38: 915-923, 1997.

10 Hardenbergh PH, Golden J, Billet A, Scott RM, Shrieve DC, Silver B, Loeffler JS and Tarbell NJ: Intracranial germinoma: the case for lower dose radiation therapy. Int J Radiat Oncol Biol Phys 39: 419-426, 1997.

11 Wolden SL, Wara WM, Larson DA, Prados MD, Edwards MS and Sneed PK: Radiation therapy for primary intracranial germcell tumors. Int J Radiat Oncol Biol Phys 32: 943-949, 1995.

12 Sawamura Y, Ikeda J, Shirato H, Tada M and Abe H: Germ cell tumours of the central nervous system: treatment consideration based on 111 cases and their long-term clinical outcomes. Eur J Cancer 34: 104-110, 1998.

13 Jensen AW, Laack NN, Buckner JC, Schomberg PJ, Wetmore CJ and Brown PD: Long-term follow-up of dose-adapted and reduced-field radiotherapy with or without chemotherapy for central nervous system germinoma. Int J Radiat Oncol Biol Phys 77: 1449-1456, 2010.

14 Bundesamt für Statistik (2017): Life expectancy in Switzerland https://www.bfs.admin.ch/bfs/de/home/statistiken/bevoelkerung/ge burten-todesfaelle/todesfaelle-sterblichkeit-lebenserwartung.html.

15 Chowdhary A, Spence AM, Sales L, Rostomily RC, Rockhill JK and Silbergeld DL: Radiation-associated tumors following therapeutic cranial radiation. Surg Neurol Int 3: 48, 2012.

16 Osuka S, Tsuboi K, Takano S, Ishikawa E, Matsushita A, Tokuuye K, Akine $\mathrm{Y}$ and Matsumura A: Long-term outcome of patients with intracranial germinoma. J Neurooncol 83: 71-79, 2007.
17 Oka H, Kawano N, Tanaka T, Utsuki S, Kobayashi I, Maezawa $\mathrm{H}$ and Fujii K: Long-term functional outcome of suprasellar germinomas: usefulness and limitations of radiotherapy. J Neurooncol 40: 185-190, 1998.

18 Sivasubramaniam V, Zebian B, Thakur B, Saran F and Chandler $\mathrm{C}$ : Germinoma recurrence in the conus medullaris 12 years after remission of primary intracranial lesion in the pituitary. J Clin Neurosci 25: 150-152, 2016.

19 Sugiyama K, Uozumi T, Arita K, Kiya K, Kurisu K, Sumida M and Harada K: Clinical evaluation of 33 patients with histologically verified germinoma. Surg Neurol 42: 200-210, 1994.

20 Kumanogoh A, Kasayama S, Kouhara H, Koga M, Arita N, Hayakawa T, Kishimoto T and Sato B: Effects of therapy on anterior pituitary functions in patients with primary intracranial germ cell tumor. Endocr J 41: 287-292, 1994.

21 Odagiri K, Omura M, Hata M, Aida N, Niwa T, Ogino I, Kigasawa $\mathrm{H}$, Ito $\mathrm{S}$, Adachi $\mathrm{M}$ and Inoue $\mathrm{T}$ : Treatment outcomes, growth height and neuroendocrine functions in patients with intracranial germ cell tumors treated with chemoradiation therapy. Int J Radiat Oncol Biol Phys 84: 632-638, 2012.

22 Saeki N, Tamaki K, Murai H, Kubota M, Yamaura A, Uchida D, Noguchi Y, Nakamura S, Tatsuno I, Wada K, Minagawa M and Yasuda T: Long-term outcome of endocrine function in patients with neurohypophyseal germinomas. Endocr J 47: 83-89, 2000.

23 Saeki N, Murai H, Kubota M, Fujimoto N and Yamaura A: Long-term Karnofsky performance status and neurological outcome in patients with neurohypophyseal germinomas. Br J Neurosurg 15: 402-408, 2001.

24 Kellie SJ, Boyce H, Dunkel IJ, Diez B, Rosenblum M, Brualdi L and Finlay JL: Intensive cisplatin and cyclophosphamidebased chemotherapy without radiotherapy for intracranial germinomas: failure of a primary chemotherapy approach. Pediatr Blood Cancer 43: 126-133, 2004.

25 Balmaceda C, Heller G, Rosenblum M, Diez B, Villablanca JG, Kellie S, Maher P, Vlamis V, Walker RW, Leibel S and Finlay JL: Chemotherapy without irradiation - a novel approach for newly diagnosed CNS germ cell tumors: results of an international cooperative trial. The First International Central Nervous System Germ Cell Tumor Study. J Clin Oncol 14: 2908-2915, 1996.

26 da Silva NS, Cappellano AM, Diez B, Cavalheiro S, Gardner S, Wisoff J, Kellie S, Parker R, Garvin J and Finlay J: Primary chemotherapy for intracranial germ cell tumors: results of the third international CNS germ cell tumor study. Pediatr Blood Cancer 54: 377-383, 2010.

27 Miller RE, Dudderidge T, Huddart R, Seckl MJ, Rustin GJ and Christmas TJ: Pathological findings after primary chemotherapy in patients undergoing simultaneous orchidectomy and retroperitoneal lymph node dissection for advanced germ cell tumours. BJU Int 111: E152-157, 2013.

28 Nakagawa H, Miyawaki Y, Tokiyoshi K, Tsuruzono K, Yamada M, Kanayama T and Hayakawa T: Pharmacokinetics of plasma and cerebrospinal fluid cisplatin in patients with malignant glioma and metastatic brain tumor after selective intraarterial or intravenous and intracarotid administration of etoposide and cisplatin. No Shinkei Geka 22: 35-42, 1994 (in Japanese).

29 Nakagawa H, Fujita T, Kubo S, Tokiyoshi K, Yamada M, Kanayama T, Hagiwara Y, Nakanomyo $\mathrm{H}$ and Hiraoka M: Difference in CDDP penetration into CSF between selective intraarterial chemotherapy in patients with malignant glioma and 
intravenous or intracarotid administration in patients with metastatic brain tumor. Cancer Chemother Pharmacol 37: 317326,1996

30 Jacobs SS, Fox E, Dennie C, Morgan LB, McCully CL and Balis FM: Plasma and cerebrospinal fluid pharmacokinetics of intravenous oxaliplatin, cisplatin and carboplatin in nonhuman primates. Clin Cancer Res 11: 1669-1674, 2005.

31 Arndt CA, Balis FM, McCully CL, Colvin OM and Poplack DG: Cerebrospinal fluid penetration of active metabolites of cyclophosphamide and ifosfamide in rhesus monkeys. Cancer Res 48: 2113-2115, 1988.

32 Niemann A, Muhlisch J, Fruhwald MC, Gerss J, Hempel G and Boos J: Therapeutic drug monitoring of methotrexate in cerebrospinal fluid after systemic high-dose infusion in children: Can the burden of intrathecal methotrexate be reduced? Ther Drug Monit 32: 467-475, 2010.

33 Peckham MJ, Barrett A, Liew KH, Horwich A, Robinson B, Dobbs HJ, McElwain TJ and Hendry WF: The treatment of metastatic germ-cell testicular tumours with bleomycin, etoposide and cis-platin (BEP). Br J Cancer 47: 613-619, 1983.
34 Ueba T, Yamashita K, Fujisawa I, Nakao S, Ooyama K, Yorihuji T, Kato SF, Seto S and Kageyama N: Long-term follow-up of 5 patients with intracranial germinoma initially treated by chemotherapy alone. Acta Neurochir 149: 897-902; discussion 902, 2007.

35 Vijayaraghavan S, Brock C, Monson JP, Snodgrass GJ, King TT, Gallagher C and Oliver RT: Does the rapid response to cisplatinbased chemotherapy justify its use as primary treatment for intracranial germ-cell tumours? Q J Med 86: 801-810, 1993.

Received April 16, 2017

Revised April 27, 2017

Accepted May 2, 2017 